\title{
Interactive comment on "MIROC-INTEG1: A global bio-geochemical land surface model with human water management, crop growth, and land-use change" by Tokuta Yokohata et al.
}

\section{Anonymous Referee \#1}

Received and published: 3 December 2019

\section{GENERAL COMMENTS}

In this manuscript, Yokohata et al. describe a model integration that brings together (mostly) process-based representations of land use decisionmaking, land surface, hydrology, vegetation, and agriculture. This is part of an important recent trend in making integrated models that actually account for the effects of changing climate and CO2 on agricultural productivity, and how that changing productivity will affect the future trajectory of land use. The manuscript is well-written, with a decent amount of technical detail, as one would hope for a paper in this journal. However, I have reservations about how the integrated model is framed at the beginning of the manuscript. For that

Printer-friendly version

Discussion paper 
reason, coupled with a number of clarifications that need to be made, I suggest that the paper be resubmitted with major revisions.

\section{SPECIFIC COMMENTS}

The beginning of the manuscript sets up a loftier goal than is actually achieved by the presented model. I got the impression that the climate system was included as a component, while in reality the demonstrated version uses offline climate forcings. This begins with the model name, which includes MIROC-a well-known climate model. This idea is reinforced in the Abstract at P1 L27-28, in the Introduction at P3 L20-22, and in Sect. 2 at P4 L8-10. In fact, it's unclear why MIROC is included at all-its only relevance to the work presented here is that it's the source of one of the five climate forcings used. It would make more sense to call the integrated model presented here INTEG1, and reserve "MIROC-INTEG1" for a future version that does actually include MIROC coupling.

In addition to these specific instances of the authors claiming an integration that does not appear to exist, the text of the Introduction sets up MIROC-INTEG1 as being able to "examine the impact of land-use change on the climate system" (P3 L25) and "quantitatively evaluate the interactions and feedback related to climate, water, crop, land use, and ecosystem" (P3 L27). While the work here gets at a proxy variable-terrestrial carbon storage - that relates to the land-atmosphere carbon flux, actually directly assessing land-use impact on climate is impossible without coupling to a climate model. It is also unclear exactly what feedbacks the authors are referring to at P3 L27, considering that most of the sub-models do not seem to be connected in a two-way manner (see Robinson et al., 2018 Fig. 2).

Coupling a climate model is clearly outside the scope of the present work, but I want to reiterate that the analyses presented ARE publication-worthy-they just need to be set up in a less misleading way.

Printer-friendly version

Discussion paper

I am also concerned by the relative lack of space spent evaluating TeLMO. Considering

\section{(}


that it is the primary piece of model development introduced in this manuscript (as opposed to integration of existing models), the authors should evaluate more than just regional and global cropland area over 12 years (Fig. 7, which by the way needs area units specified). At the very least, similar analyses need to be presented for pasture and forest area.

I also have a number of other issues I would like the authors to address in a revised version.

- Is livestock feed production included in crop demand?

- Why do protected areas protect only from bioenergy and not food crops or pasture?

- Sect. A.5 (P19 L15-21): What is "irrigation water stock" and how does it relate to things calculated in HiGWMAT? It seems completely separate, since the controlling parameter Irr_capacity "is estimated at each cell of the grid by MCMC" (P19 L20-21).

- By using the Kato \& Yamagata (2014) biofuel yields map, it seems that changes in biofuel yield are not considered. Could this be added by scaling based on changing yield of wheat and/or maize?

- Historical domestic and industrial water extractions are taken from FAOSTAT; how are projected extractions calculated?

- With regard to adjustment factors for matching LUH2 or AIM land use areas/demand: What is the justification for using a gridcell-level adjustment factor for cropland but region-level adjustment factors for others?

- Fig. 2 should be revised to separate (a) input data coming from outside the model system and (b) data being moved between sub-models. Generally, using different kinds of boxes (rounded rectangles vs. circles, for instance) for models vs. data would be helpful. "Atmosphere" should be added to the arrow pointing to Land Ecosystem.

TECHNICAL CORRECTIONS

Printer-friendly version

\section{Discussion paper}

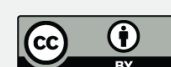


- P3 L2: Misspelling: "temperture"

- Throughout: "Chapters" should be referred to as "sections"

- P6 L25: Unnecessary comma in "et al., (2011)"

- P11 L21: "LUH2h2v"

- P12 L6: What is "mascon"?

- P13 L10: Closing parenthesis should come after "satellite"

- P14 L1: "reproducibility" doesn't seem like the right word. Perhaps "performance"?

- P14 L13: 2a should be 8b

- P14 L20: "global average" should be "global total" or just "total"

- P16 L15: I'm unclear as to what this explanation means: "Soil carbon is less impacted by the land-use change compared to the above-ground biomass, likely because of the carbon supply from crops in the VISIT calculation."

- P16 L20-22: It is unclear how increasing above-ground biomass would negatively affect ecosystem services.

- P21 L9-10: This is unclear; please revise.

- P28 L6: Citation missing

- Fig. 4: Labels (a) and (b) should be referenced in caption.

- Fig. 10: Y-axis units?

- Fig. B-1: (1) Bin boundaries should be labeled in terms of real units. (2) What year(s) are being compared? At what resolution? (Include this info in caption, not just main text.)

WORKS CITED IN REVIEW 
Robinson, D.T., Di Vittorio, A., Alexander, P., Arneth, A., Barton, C.M., Brown, D.G., Kettner, A., Lemmen, C., O'Neill, B.C., Janssen, M., Pugh, T.A.M., Rabin, S.S., Rounsevell, M., Syvitski, J.P., Ullah, I., Verburg, P.H., 2018. Modelling feedbacks between human and natural processes in the land system. Earth Syst. Dynam. 9, 895-914. doi:10.5194/esd-9-895-2018.

Interactive comment on Geosci. Model Dev. Discuss., https://doi.org/10.5194/gmd-2019-184, 2019. 